\title{
Inactivation of the BSE agent by the heat and pressure process for manufacturing gelatine
}

\author{
A. H. Grobben, P. J. Steele, R. A. Somerville, D. M. Taylor, B. E. C. Schreuder
}

\begin{abstract}
Dietary exposure to the bovine spongiform encephalopathy (BSE) agent is the probable cause of variant Creutzfeldt-Jakob disease in people. The industrial manufacturing process for the production of gelatine and colloidal protein by the heat and pressure process was downscaled accurately and its capacity to remove or inactivate BSE infectivity was investigated. Gelatine was made from bones experimentally contaminated with mouse brain infected with the $301 \mathrm{~V}$ strain of mouse-passaged BSE agent in which the infective titre was $10^{8 \cdot 7} \mathrm{ID} 50 / \mathrm{g}$. No infectivity was detected in the extracted protein $\left(\leq 10^{0.45} \mathrm{ID} 50 / \mathrm{g}\right)$, and the calculated clearance factor was $10^{6.5}$ ID50 or more.
\end{abstract}

Veterinary Record (2005) $157,277-281$

\section{A. H. Grobben, BSc,}

Delft Gelatin, p/a

Watergraaflaan 22,

4731 WH Oudenbosch,

The Netherlands

P. J. Steele, BSc,

R. A. Somerville, $\mathrm{PhD}$,

Neuropathogenesis Unit, Institute for Animal

Health, West Mains Road,

Edinburgh EH9 3JF

D. M. Taylor, $\mathrm{PhD}, \mathrm{MBE}$,

Sedecon 2000, 147

Oxgangs Road North,

Edinburgh EH13 9DX

B. E. C. Schreuder, DVM,

$\mathrm{PhD}$,

Institute for Animal

Science and Health,

PO Box 65, $8200 \mathrm{AB}$

Leylystad, The

Netherlands

Mr Steele's present

address is the Moredun

Research Institute,

Pentlands Science Park,

Bush Loan, Penicuik

EH26 0PZ
BOVINE spongiform encephalopathy (BSE) belongs to a group of fatal neurological diseases of animals and human beings commonly known as the transmissible spongiform encephalopathies (TSEs). TSEs can be transmitted within and between species, and the precise nature of their unconventional causal agents is still uncertain (Somerville 2002). Most infectivity is found in the tissues of the central nervous system (CNS), but other tissues can also be infected (Hadlow and others 1982, Wells and others 1998, 1999). BSE was first described in the UK in 1987 (Wells and others 1987) and the resultant epidemic peaked in 1993, at about the same time as the first cases were reported in continental Europe. A new variant form of Creutzfeldt-Jakob disease (vCJD) was subsequently diagnosed in the UK in 1996 (Will and others 1996), and the causal agent was shown to be identical to the BSE agent but different from other TSE agents that had been characterised (Bruce and others 1997). Concerns for human health were heightened not only about materials coming directly from abattoirs, but also about any product manufactured from raw materials of bovine origin, including gelatine produced from cattle bones and hides. In EU countries, steps were taken to control the possible exposure of the public to potentially BSE-contaminated products of bovine origin, including the exclusive use of clinically healthy animals, the removal of potentially highly infected CNS tissue (Anon 1989, EC 1999, $2000,2001)$, and the application of processes with the potential to reduce infectivity levels (CPMP 1992, 1998).

Gelatine, a soluble protein made by the partial hydrolysis of collagen (Jones 1987a, Grobben and others 2003) is used in many pharmaceutical products and food products because of its unique gel forming properties; it also binds solid particles and stabilises emulsions of oily droplets or solid particles (Jones 1987b). Industrially, gelatine is manufactured from collagen-rich animal by-products, obtained from animals fit for human consumption (EC 1999), that are available in sufficient quantity and quality at reasonable cost; these are the bones of cattle and pigs, and hides of cattle and the skins of pigs. Most of the gelatine used in food products is derived from pigskins, but cattle bones are used to produce the gelatine used in pharmaceutical applications, such as hard and soft capsules, coatings and tablets (Wood 1977, Jones 1987a, Goedknegt and Grobben 2003). The collagen in bone can be denatured and hydrolysed by chemical processes in which the bones are treated with acid and alkali or by a thermal process in which the bones are treated with hot saturated steam.

Experiments intended to characterise the properties of the scrapie agent (Gordon and others 1939, Stamp and others 1959, Butler and Smith 1960, Pattison and Millson 1961a, b, Chandler 1963, Hunter and Millson 1964a, b) and the transmissible mink encephalopathy agent (Burger and Hartsough
1965) showed that they were highly resistant to methods that inactivated many conventional pathogens, but that autoclaving at temperatures of 118 to $126^{\circ} \mathrm{C}$ appeared to be effective (MacKay and others 1960, Pattison and Millson 1961b, Hunter and Millson 1964b). The iatrogenic transmission of CJD via surgical instruments (Duffy and others 1974, Bernoulli and others 1977, Foncin and others 1980, Will and Matthews 1982) stimulated investigations by Kimberlin and others (1983) and Brown and others (1986) of methods to inactivate the CJD agent, which resulted in the UK standard for the inactivation of CJD material by porous load autoclaving at 134 to $138^{\circ} \mathrm{C}$ for 18 minutes (DHSS 1984) and the USA standard of $132^{\circ} \mathrm{C}$ for one hour (Rosenberg and others 1986). The hypothesis that inadequate inactivation of the scrapie agent during rendering gave rise to BSE, through meat and bone meal (Wilesmith and others 1988), encouraged similar studies on the inactivation capacity of rendering processes by Taylor and others $(1995,1997)$ and Schreuder and others (1998), resulting in the EU standard for rendering of $133^{\circ} \mathrm{C}$ at 3 bar for 20 minutes (EC 1994, 1996).

A new autoclaving process for the manufacture of gelatine was developed in the 1990s to incorporate these standards, with the first autoclaving step being carried out in saturated steam at a minimum of 3 bar and $133^{\circ} \mathrm{C}$ for at least 20 minutes. However, a study by Taylor and others (1994) showed that these conditions may be ineffective if the infective material is in a dehydrated state (Asher and others 1987). Because the drying of the degreased bone in a stream of hot air during the gelatine manufacturing process may mimic this effect, it was decided to test the autoclaving process for the manufacture of gelatine experimentally.

A scaled-down model of the industrial process that could be run in the laboratory was developed, in which the process conditions were precisely the same as the minimum conditions that were applied in the industrial process. The starting material was the crushed bone material that is used in the industrial process. When the experimental protocol was being developed in 1997, the vertebral column from which the spinal cord was not always removed, was still allowed in the bones used for gelatine manufacture. The European gelatine manufacturers had voluntarily ceased using the head of cattle since 1997, and the spinal cord of cattle since 1998 (Gelatin Manufacturers of Europe [GME], personal communication). In 2000, the removal of the spinal cord of cattle became mandatory throughout the EU (EC 2000,), and this was followed, in 2001, by the requirement to remove the entire vertebral column (EC 2001). Until 1998, the backbone with the spinal cord of the BSE-infected cow could be incorporated with the bones for the manufacture of gelatine. In the experiments, pieces of intact vertebral column of a calf were therefore added to the crushed bones in a ratio 1:3. The bones were 
TABLE 1: Titration of $301 \mathrm{~V}$ infectivity in macerated mouse brain

\begin{tabular}{lcc}
-Log dilution & Injected & Number of mice \\
\hline 5 & 12 & Positive \\
6 & 12 & 12 \\
7 & 11 & 12 \\
8 & 12 & 4 \\
9 & 12 & 2 \\
\hline
\end{tabular}

spiked with mouse brain infected with the $301 \mathrm{~V}$ TSE strain; some of it was injected into the spinal cord in the calf's vertebral column to imitate infected spinal cord, and some was smeared over the crushed bones to mimic cross-contamination. The $301 \mathrm{~V}$ strain of mouse-passaged BSE was selected because it has a high titre of infectivity and is the most heatresistant strain that has been identified (Taylor and others 2002).

\section{MATERIALS AND METHODS}

\section{Preparation of $\mathbf{3 0 1 V}$-spiked raw material}

The starting material consisted of $750 \mathrm{~g}$ of fresh industrial crushed bovine bone and a $254 \mathrm{~g}$ section of intact calf vertebral column. To this was added macerated whole brain from VM mice terminally infected with $301 \mathrm{~V} ; 5.6 \mathrm{~g}$ of brain were macerated with a Heidolph automatic stirrer and pestle and $2.4 \mathrm{~g}$ of the undiluted brain macerate were injected into the spinal cord of the calf to mimic the situation in which BSEinfected spinal column might be present among the crushed bones used by the gelatine industry; $1.5 \mathrm{~g}$ of the brain macerate was smeared onto the surface of the crushed bone pieces to mimic the situation in which bone might have become cross-contaminated with BSE-infected tissue. The backbone was sawn into pieces of approximately the same size as the crushed bone and the two pools of infected bone material were mixed together.

\section{Scaled down gelatine manufacturing process}

Degreasing Uninfected bone material (600 g) was stirred for 20 minutes in water at $80^{\circ} \mathrm{C}$ and then the emulsion of fat in water was decanted into a 3 litre double-walled beaker, which was kept at 80 to $85^{\circ} \mathrm{C}$ by pumping hot water through the beaker wall. The infected bone material was placed in a perforated basket and immersed in the fat emulsion prepared by the initial degreasing step. The infected bones were degreased for 20 minutes at 80 to $85^{\circ} \mathrm{C}$ with stirring. During this process, 1 litre of emulsion was pumped from the beaker and replaced by 1 litre of hot water at $80^{\circ} \mathrm{C}$. The final emulsion was pumped out and replaced by 2 litres of water at $80^{\circ} \mathrm{C}$. After stirring for three minutes, the water was pumped out and the bones were drained. Loose soft tissue was removed with forceps to mimic its industrial removal by hydrocyclones, and the wet degreased bone was then dried for 50 minutes in hot air at $80^{\circ} \mathrm{C}$. The bone was then sieved through a $4 \mathrm{~mm}$ sieve to remove any remaining loose soft tissue and small bone particles.

Autoclaving and extraction From these initial steps $240 \mathrm{~g}$ of dried, degreased bone chips were obtained. They were placed in a down-scaled stainless steel model of an industrial autoclave equipped with inlets and outlets for steam and water, and five calibrated thermocouples placed at different positions in the autoclave were connected to a temperature recorder. The autoclave was preheated to $133^{\circ} \mathrm{C}$ for $17.5 \mathrm{~min}-$ utes with steam from a generator at a pressure of 4.2 bar. The bone was then autoclaved with saturated steam for $20 \mathrm{~min}$ utes at a temperature between $132 \cdot 3$ and $134 \cdot 8^{\circ} \mathrm{C}$, after which

\begin{tabular}{|c|c|c|}
\hline -Log dilution & Injected & Positive \\
\hline 0 & 16 & 0 \\
\hline 1 & 17 & 0 \\
\hline 2 & 15 & 0 \\
\hline 3 & 15 & 0 \\
\hline 4 & 17 & 0 \\
\hline
\end{tabular}

the steam inlet was closed and the outlet was gradually opened. After seven minutes the temperature in the autoclave was below $100^{\circ} \mathrm{C}$, and $200 \mathrm{ml}$ of extraction water was pumped in and circulated for 10 minutes. The autoclave was drained for 10 minutes, and $175 \mathrm{ml}$ of a 4 per cent gelatine solution was obtained. The temperatures at the five positions were recorded automatically every 20 seconds.

\section{Determination of the infectivity titres of the samples}

Serial 10 -fold dilutions of the $301 \mathrm{~V}$ brain homogenate and gelatine solution were prepared in physiological saline and injected intracerebrally into groups of VM mice $(20 \mu \mathrm{l}$ per mouse). The animals were scored according to standard protocols to detect clinical signs of neurological disease (Dickinson and others 1968), and they were culled if they developed unequivocal signs of neurological disease. Mice that did not develop clinical disease were culled at 607 or 623 days after they had been injected. The brains of all the animals were removed and fixed in formol-saline, and sections were cut and stained with haematoxylin and eosin. The sections were examined microscopically for the spongiform lesions that are pathognomonic for TSE infection in mice (Fraser and Dickinson 1968). From the ratios of positive to negative animals in each dilution group, the titres of infectivity in the samples were calculated by the method of Kärber (1931) and by the generalised linear model with C-loglog link and binomial distribution of the data (GLM) (Oberthür and others 2001).

\section{RESULTS}

Tables 1 and 2 show the results of the mouse bioassays of the $301 \mathrm{~V}$ brain material and the extracted gelatine, respectively. The infective titres for the mouse brain were $10^{8 \cdot 7} \mathrm{ID} 50 / \mathrm{g}$ by the Kärber method and $10^{8 \cdot 4} \mathrm{ID} 50 / \mathrm{g}$ by the GLM method. The infectivity of the extracted gelatine was below the detection limits of up to $10^{0.45} \mathrm{ID} 50 / \mathrm{ml}$ by the Kärber method, and up to $10^{0.2} \mathrm{ID} 50 / \mathrm{ml}$ by the GLM method.

Infectivity clearance factors (CFs) were calculated from the measured titres by the equation:

$$
\mathrm{CF}=\left(\mathrm{m}_{\text {brain spike }} \times \mathrm{IT}_{\text {brain spike }}\right) /\left(\mathrm{m}_{\text {gelatine }} \times \mathrm{IT}_{\text {gelatine }} \times \mathrm{C}_{\text {samples }}\right)
$$

where $\mathrm{m}_{\text {brain spike }}$ and $\mathrm{m}_{\text {gelatine }}$ are the amount of brain used to spike the bone and the amount of the gelatine obtained, respectively, $\mathrm{IT}_{\text {brain spike }}$ and $\mathrm{IT}_{\text {gelatine }}$ are the titres of the brain used to spike the bones, respectively, and the titre of the gelatine obtained and $\mathrm{C}_{\text {samples }}$ is the correction factor for the samples taken during the processing.

A summary of the experimental data and the calculated CFs are shown in Table 3. None of the mice inoculated with the extracted gelatine sample developed neurological disease. A theoretical maximum titre was calculated for this sample by using the method of Kärber (1931), by assuming that four of 16 animals could have died in a 10-times concentrated solution and that all the animals could have died in a 100times concentrated solution. A maximum titre was also calculated by using GLM (Oberthür and others 2001). On the 
TABLE 3: Summary of the experimental data and the calculated clearance factors (CFS)

\begin{tabular}{|c|c|c|c|c|c|c|}
\hline $\begin{array}{l}\text { Calculation } \\
\text { method }\end{array}$ & $\begin{array}{r}\text { 301V-infe } \\
\text { Amount (g) }\end{array}$ & $\begin{array}{l}\text { ected brain } \\
\text { Infective } \\
\text { titre (ID50/g) }\end{array}$ & $\begin{array}{r}\text { Extracted } \\
\text { Amount (ml) }\end{array}$ & $\begin{array}{l}\text { gelatine } \\
\text { Infective } \\
\text { titre (ID50/g) }\end{array}$ & $\begin{array}{c}\text { Correction } \\
\text { factor for } \\
\text { samples taken }\end{array}$ & $\begin{array}{c}\text { Total } \\
\text { CF (ID50) }\end{array}$ \\
\hline Kärber & 3.91 & $10^{8 \cdot 7}$ & 175 & $\leq 10^{0.45}$ & $1 \cdot 1$ & $\geq 10^{6 \cdot 6}$ \\
\hline GLM & 3.91 & $10^{8 \cdot 4}$ & 175 & $\leq 10^{0 \cdot 2}$ & $1 \cdot 1$ & $\geq 10^{6 \cdot 5}$ \\
\hline
\end{tabular}

GLM Generalised linear model with C-loglog link and binomial distribution of the data basis of the amount of extract obtained, the calculated $\mathrm{CF}$ for the heat and pressure process was at least $10^{6 \cdot 6}$ ID50 by the Kärber method and at least $10^{6.5}$ ID50 by the GLM method. As the se for the infective titre calculated by GLM was $10^{0 \cdot 17}$, the two calculations gave results that were not significantly different. To extract the gelatine, $200 \mathrm{ml}$ of water were pumped into the autoclave, and $175 \mathrm{ml}$ of extract was obtained. The remainder was absorbed by the bone. Most probably the bone also absorbed some condensate from the steam and on the basis of earlier experiments (A. H. Grobben, unpublished observations) it was estimated that approximately $50 \mathrm{~g}$ of extract remained with the bone in the autoclave. When the calculations were corrected for this, the $\mathrm{CF}$ of the process was at least $10^{6 \cdot 4}$ ID50, which does not differ significantly from the above values.

\section{DISCUSSION}

Although the spiked raw material contained a very high level of infectivity ( $10^{9 \cdot 3} \mathrm{ID} 50 / \mathrm{kg}$ bone), none was detectable in the gelatine extract produced by the experimental steps of degreasing, autoclaving and extraction. These steps represent only the initial stages of the industrial process in which there are several additional purification steps, including filtration and ion-exchange, that could further reduce the level of infectivity (Grobben and others 2004; A. H. Grobben, R. G. Rohwer, unpublished observations). However, the results of this study show that the initial steps alone can reduce hightitre BSE-derived infectivity by at least $10^{6.5} \mathrm{ID} 50$. This degree of inactivation is supported by the results of several earlier inactivation studies (Kimberlin and others 1983, Brown and others 1986, Taylor and others 1994).

In developing the scaled-down production of gelatine, consideration was also given to the factors that would optimise its capacity to inactivate the BSE agent. There is evidence that the efficiency with which TSE agents are inactivated by autoclaving can be influenced by a number of factors that can either enhance or reduce the efficiency. These factors are the strain of TSE agent used, the sterilising temperature, the period

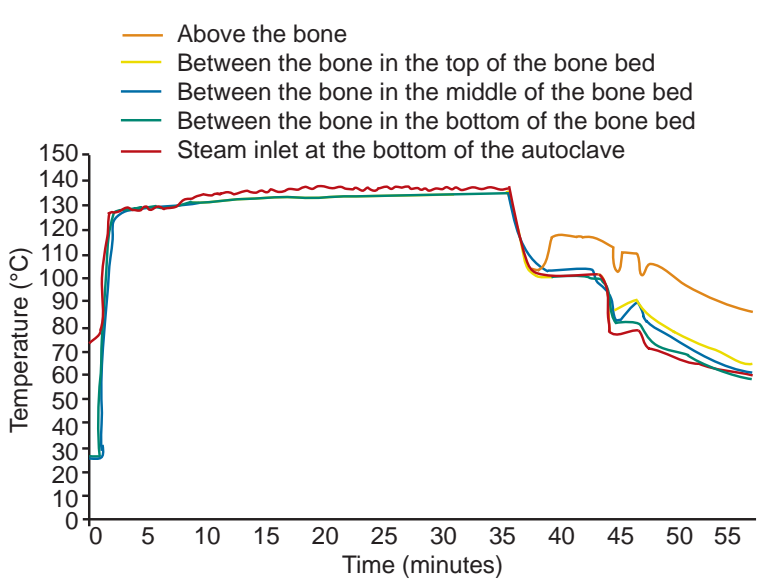

of exposure, the water content of the sample, the rapidity of the heating process and the prior exposure of the material to conditions under which proteins would be fixed, including fixation by dry heat, steam, ethanol, formaldehyde and glutaraldehyde. These factors are discussed below, referring to the data in the literature and to their implementation in the process.

Different strains of TSE agent differ in their degree of resistance to inactivation by autoclaving (Dickinson and Taylor 1978, Kimberlin and others 1983, Taylor 1999, Taylor and others 2002). The data of Schreuder and others (1998) indicated that the BSE agent is relatively thermostable. In the experiment reported here, the mouse-passaged $301 \mathrm{~V}$ strain of BSE agent was used; this is the most thermostable strain observed to date (Taylor 1999, Taylor and others 2002).

Kimberlin and others (1983), Rohwer (1984), Taguchi and others (1991) and Schreuder and others (1998) showed that the rate of inactivation increases with temperature; this was recently confirmed by Somerville and others (2002), who also showed that each strain, like conventional microorganisms, appears to encode a different threshold temperature at which inactivation will occur. The process temperature of $133^{\circ} \mathrm{C}$ selected in the heat and pressure process was fractionally above the optimal for the gelatine process, but was selected to be high enough to have a potentially TSE-inactivating effect.

Kimberlin and others (1983), Rohwer (1984) and Schreuder and others (1998) also showed that the degree of inactivation initially increases with time, with a linear relationship between time and the logarithm of the infectivity (Casolari 1998). As the time increases, however, the rate of inactivation decreases and it reaches a plateau after which no further inactivation occurs (Kimberlin and others 1983, Rohwer 1984, Taylor and others 1998). The processing time in the process tested was shorter than in several inactivation experiments, but approximately the same as recommended by the DHSS (1984) and the EU standard (EC 1994, 1996) for TSE autoclave sterilisation. The results confirmed that the selected time and temperature were sufficient to obtain a large decrease of infectivity.

Brown and others $(1986,1990)$ and Taylor and others (1996) showed that dry heat is much less effective than autoclaving in steam, and according to Taylor (2003) autoclaving a homogenate could be even more effective than autoclaving tissue. In the experimental production of gelatine, the bone chips were preheated by a flow of saturated steam passing through them, and the open matrix formed by the bone chips in the autoclave allowed the steam to penetrate them thoroughly and, by condensing on them, saturate them with water. The subsequent autoclaving in saturated steam ensures that a hydrated environment is maintained. The high water content of the bone throughout the process, in combination with the high temperature, promotes both the inactivation of TSE agents and the denaturation and hydrolysis of collagen to gelatine.

A short heating period and a steep heating profile with a continuously increasing temperature until the final temperature is reached are apparently optimal for TSE inactivation. The importance of reaching the autoclaving temperature rapidly was mentioned by Kimberlin and others (1983), and it has been shown that temperature variations during heating up resulted in less inactivation ( $10^{4 \cdot 2}$ ID50) than in the experiment described here (A. H. Grobben, P. J. Steele, unpublished observations). Because of the high latent heat of saturated steam and its large heat transfer coefficient during condensation, a large amount of heat could be transferred quickly to the bone chips. In addition, the open structure and small particle size of the bone chips allowed heat to penetrate effectively. Because the temperature of the steam entering the autoclave was always higher than the temperature of the bone chips, their temperature increased continuously until 
the equilibrium temperature was reached and then remained approximately constant throughout the 20 minutes of autoclaving (Fig 1).

The physical history of the starting material, that is, drying and heating, is an important factor influencing the final inactivation result. The infectivity in brain suspensions dried on glass or metal, and in samples of smeared and dried brain macerates, partially resisted inactivation by steam autoclaving (Asher and others 1987, Taylor and others 1994, Taylor 1999). When samples were autoclaved twice, there was much less inactivation during the second autoclaving cycle (Taguchi and others 1991, Taylor and others 1998), an effect which was considered to be due to the production of a thermostable subpopulation of the agent; Somerville and others (2002) suggested that it may be the result of a competitive parallel stabilisation reaction. These findings are relevant when trying to ensure that materials should not be allowed to dry before they are autoclaved. In the EU, fresh bones for manufacturing gelatine must be processed within 24 hours of collection (EC 1999). This short period and the high water content of the bones should ensure that any BSE-infected adventitious tissue on the bones remains moist until processing begins. During the degreasing process that precedes autoclaving, the wet bone chips are dried in a stream of hot air. During this step, which was included in the procedure described here, it would be possible for the infective agent to dry on to the surfaces of the bones and possibly be stabilised by exposure to hot air at $80^{\circ} \mathrm{C}$. However, the results reported here, and the results described by Grobben and others (2004), indicate that insufficient (if any) infective agent dries (or becomes stabilised) on to the bones to impair the efficiency of the autoclaving process.
Chemical pretreatment of the starting material, such as treatment with formaldehyde (Taylor and McConnell 1988, Brown and others 1990), can increase the thermostability of TSE agents. However, in all the gelatine manufacturing processes used in the EU, the bones are degreased with hot water and no chemical pretreatment is applied. In countries where solvent degreasing is still used, the results of this study cannot be applied, because the treatment with solvent might increase the resistance of the agent against inactivation.

It can be concluded that by selecting optimal inactivation conditions and avoiding conditions and factors that might reduce the efficiency of inactivation, a process for the manufacture of gelatine has been developed that inactivates most TSE infectivity.

\section{ACKNOWLEDGEMENTS}

This study was supported by the European Commission, Quality of Life and Management of Living Resources, Key action 1 'Food, nutrition and health' programme and by the GME. The authors thank Dr M. Schoentjes of sKW Gelatin and Specialities, Mr R. Schrieber of DGF Stoess, and Mr J. Thomsen of GME, for their efforts in setting up this study and their contributions to the protocol for the study. The authors also thank Professor D. Dormont, Dr B. Oesch, Ms K. Fernie, Dr R. Rohwer, Dr G. de Baere and Dr L. Manuelidis for their valuable advice during the development of the study. The authors thank Dr Aline de Koeijer of the Institute for Animal Science and Health in Lelystad (the Netherlands), for the calculation of the infectivity by the GLM.

\section{References}

ANON (1989) The Bovine Offal (Prohibition) Regulations 1989. SI 1989 number 2061. London, The Stationery Office

ASHER, D. M., POMEROY, K. L., MURPHY, L., GIBBS, D. J. \& GAJDUSEK, D. C. (1987) Attempts to disinfect surfaces contaminated with etiological agents of the spongiform encephalopathies. Abstract R18.14. In Abstracts of the VIIth International Congress of Virology. Edmonton, Canada. August 9 to $14,1987 . \mathrm{p} 147$

BERNOUlLI, C., SIEGFRIED, J., BAUMGARTNER, G., REGLI, F., RABINOWICZ, T., GAJDUSEK, D. C. \& GIBBS, J. C. (1977) Danger of accidental person-to-person transmission of Creutzfeldt-Jakob disease by surgery. Lancet i, 478-479

BROWN, P., LIBERSKI, P. P., WOLFF, A. \& GAJDUSEK, D. C. (1990) Resistance of scrapie infectivity to steam autoclaving after formaldehyde fixation and limited survival after washing at $360^{\circ} \mathrm{C}$ : practical and theoretical implications. Journal of Infectious Diseases 161, 467-472

BROWN, P., ROHWER, R. G. \& GADJUSEK, D. C. (1986) Newer data on the inactivation of scrapie virus or Creutzfeldt-Jakob disease virus in brain tissue. Journal of Infectious Diseases 153, 1145-1148

BRUCE, M. E., WILL, R. G., IRONSIDE, J. W., MCCONNEL, I., DRUMMOND, D., SUTTIE, A., MCCARDLE, L., CHREE, A., HOPE, J., BIRKETT, C. COUSENS, S., FRASER, H. \& BOSTOCK, C. J. (1997) Transmissions to mice indicate that 'new variant' CJD is caused by the BSE agent. Nature 389, 498501

BURGER, D. \& HARTSOUGH, G. R. (1965) Encephalopathy of mink. II experimental and natural transmission. Journal of Infectious Diseases 115, 393-399 BUTLER, E. J. \& SMITH, W. (1960) An attempt to separate the scrapie agent from brain tissue. Veterinary Record 72, 417-418

CASOLARI, A. (1998) Heat resistance of prions and food processing. Food Microbiology 15, 59-63

CHANDLER, R. L. (1963) Experimental scrapie in the mouse. Research in Veterinary Science 4, 276-285

CPMP (1992) Guidelines for minimising the risk of transmitting agents causing spongiform encephalopathy via medicinal products (guidelines by the CPMP) EEC regulatory documents, 1991, Brussels, Belgium. Biologicals 20, $155-158$

CPMP (1998) Note for guidance on minimising the risk of transmitting animal spongiform encephalopathy agents via medicinal products (revision of guidelines by the CPMP) CPMP/BWP/1230/98. Brussels, European Community DHSS (1984) Management of patients with spongiform encephalopathy,
Creutzfeldt-Jakob disease (CJD). DHSS Circular DA 84, 16

DICKINSON, A. G., MEIKLE, V. M. H. \& FRASER, H. (1968) Identification of a gene which controls the incubation period of some strains of scrapie agent in mice. Journal of Comparative Pathology 78, 293-299

DICKINSON, A. G. \& TAYLOR, D. M. (1978) Resistance of scrapie agent to decontamination. New England Journal of Medicine 299, 1413-1414 DUFFY, P., WOLF, J., COLLINS, G., DE VOE, A. G., STREETEN, B. \& COWEN, D. (1974) Possible person-to-person transmission of Creutzfeldt-Jakob disease. New England Journal of Medicine 290, 692-693

EC (1994) Commission Decision 94/382/EEC of 27 June 1994 on the approval of alternative heat treatment systems for processing animal waste with a view to the inactivation of spongiform encephalopathy agents. Official Journal of the European Communities L 172, 25-28

EC (1996) Commission Decision 96/449/EEC of 18 July 1996 on the approval of alternative heat treatment systems for processing animal waste with a view to the inactivation of spongiform encephalopathy agents. Official Journal of the European Communities L 184, 43-46

EC (1999) Commission Decision 99/724/EC of 28 October 1999 amending Annex II to Council Directive 92/118/EEC laying down animal health and public health requirements governing trade in and imports into the Community of products not subject to the said requirements laid down in specific Community rules referred to in Annex A (I) to Directive 89/662/EEC and, as regards pathogens, to Directive 90/425/EEC. Official Journal of the European Communities L 290, 32-40

EC (2000) Commission decision 2000/418/EC of 29 June 2000 regulating the use of material presenting risks as regards transmissible spongiform encephalopathies and amending Decision 94/474/EC. Official Journal of the European Communities. L 158, 76-82

EC (2001) Regulation (EC) number 999/2001 of the European Parliament and of the Council of 22 May 2001 laying down rules for the prevention, control and eradication of certain transmissible spongiform encephalopathies. Official Journal of the European Communities L 147, 1-40

FONCIN, J., GACHES, J., CATHALA, F., EL SHERIF, E. \& LE BEAU, J. (1980) Transmission iatrogène interhumaine possible de maladie de CreutzfeldtJakob avec atteinte de grains du cervelet. Révisions Neurologique (Paris) 136, 280

FRASER, H. \& DICKINSON, A. G. (1968) The sequential development of the brain lesions of scrapie in three strains of mice. Journal of Comparative Pathology 78, 301-311 